\title{
Testosterone, sex hormone-binding globulin, calculated free testosterone, and oestradiol in male vegans and omnivores
}

\author{
BY TIMOTHY J. A. KEY \\ Cancer Epidemiology Unit, Imperial Cancer Research Fund, Gibson Building, Radcliffe Infirmary, \\ Oxford $O X 26 H E$ \\ AND LIANE ROE AND MARGARET THOROGOOD \\ General Practice Research Group, Imperial Cancer Research Fund, Department of Community \\ Medicine \& General Practice, Gibson Building, Radcliffe Infirmary, Oxford OX2 $6 \mathrm{HE}$ \\ AND JOHN W. MOORE, GRAHAM M. G. CLARK AND DENNIS Y. WANG \\ Clinical Endocrinology Laboratory, Imperial Cancer Research Fund, PO Box 123, \\ Lincoln's Inn Fields, London WC2A $3 P X$
}

(Received 1 September 1989 - Accepted 19 January 1990)

\begin{abstract}
Total testosterone (T), total oestradiol (E2) and sex hormone-binding globulin (SHBG) concentrations were measured in plasma samples from fifty-one male vegans and fifty-seven omnivores of similar age. Free $T$ concentration was estimated by calculation. In comparison with the omnivores, the vegans had $7 \%$ higher total T $(P=0.250), 23 \%$ higher SHBG $(P=0.001), 3 \%$ lower free $T(P=0.580)$, and $11 \%$ higher E2 $(P=0$-194). In a subset of eighteen vegans and twenty-two omnivores for whom $4 \mathrm{~d}$ diet records were available, there were statistically significant correlations between $T$ and polyunsaturated fatty acids ( $r$ 0.37), SHBG and fat $(r 0.43$ for total fat, 0.46 for saturated fatty acids and 0.33 for polyunsaturated fatty acids), and SHBG and alcohol ( $r-0 \cdot 39)$. It is concluded that a vegan diet causes a substantial increase in SHBG but has little effect on total or free $T$ or on $E 2$.
\end{abstract}

Sex hormones: Vegans: Fat: Alcohol

It has been suggested that plasma levels of testosterone ( $T$ ) may affect the risk of developing prostate cancer (Henderson et al. 1982). Both international correlation studies and casecontrol studies have shown that an increased consumption of animal products is associated with an increased risk of prostate cancer, and some studies have suggested that vegetarian diets can reduce plasma $T$ (Rose, 1986). Vegans eat no animal products at all, and it might be expected that any physiological effects of a vegan diet would be more extreme than those of a vegetarian diet. The primary purpose of the current study was to measure the concentration of $T$ in plasma samples from a substantial number of male vegans and omnivores to test the hypothesis that the mean $T$ concentration would be lower in the vegans. Since the biologically active fraction of $T$ is probably the non-protein-bound fraction or 'free' $T$ (Anderson, 1974; Mendel et al. 1989), we estimated this variable by calculation. Subsidiary hypotheses tested were that sex hormone-binding globulin (SHBG) would be positively correlated with dietary fibre (Adlercreutz et al. 1987; Bishop et al. 1988), and that oestradiol (E2) would be inversely correlated with dietary fibre (Goldin et al. 1982).

\section{SUBJECTS AND METHODS}

The subjects were a subset of participants in a nationwide prospective study (see Thorogood et al. 1987). Approximately 6000 vegetarians and 5000 omnivores were 
recr ted between September 1980 and January 1984. The vegetarian group included 352 veg .ns, of whom 161 were men. At recruitment subjects completed a brief questionnaire covering demographic information, medical history, diet type, and frequency of consumption of alcoholic drinks and some foods. From April 1984 to January 1986 all participants under the age of 70 years were sent a kit consisting of a $10 \mathrm{ml}$ heparinized tube, a syringe, and an explanatory letter to them and to their general practitioner. Doctors were asked to take a blood sample and post it to the laboratory. Blood samples were received from 3300 subjects, of whom sixty were male vegans. On receipt, plasma was separated and stored at $-20^{\circ}$. Between September 1985 and July 1986 a 4 d diet record was sent to all participants and 5500 were returned. Of these, twenty-five were from male vegans who had previously sent in a blood sample.

Hormone concentrations were measured in all sixty samples of stored plasma from male vegans and from a similar number (sixty-seven) of male omnivores in the same age range as the vegans. Classification of subjects as vegans or omnivores was based on the subjects' replies to the short recruitment questionnaire. For those subjects who returned the $4 \mathrm{~d}$ diet record, this provided follow-up information (subsequent to the blood sample) on their diet type. At recruitment, $37 \%$ of the vegans had followed a vegan diet for more than 5 years.

Subjects were excluded from the current analyses if, at recruitment, they were current smokers (six vegans, two omnivores), were currently using long-term medication (two vegans, seven omnivores), had any history of cardiovascular disease (one vegan, one omnivore), or had missing values for weight and height (one omnivore). One further vegan subject was excluded because his plasma $T$ concentration was very low (see p. 113). The exclusions left values for fifty-one vegans and fifty-seven omnivores for analysis (some subjects were excluded under more than one criterion).

It should be noted that the questionnaire information was not collected at the same time as the blood. Information on general subject characteristics, medical history, smoking, height and weight, and usual alcohol intake was collected on average 44 months (range 30-65 months) before the blood; the $4 \mathrm{~d}$ diet record, which was used to calculate nutrient intakes (including alcohol intake during those $4 \mathrm{~d}$ ) for a subset of the subjects, was collected on average 15 months (range 9-23 months) after the blood. (The correlation between the two measures of alcohol intake was 0.61 , two-sided test $P<0.001$.)

\section{Hormone assays}

Total $\mathrm{T}$ concentration was measured with a non-extraction double-antibody radioimmunoassay kit (Sorin Biomedica (UK) Ltd, Ely). SHBG was measured with an immunoradiometric assay kit (Farmos Diagnostica, Oulunsalo, Finland). E2 was measured with a charcoal separation radioimmunoassay kit (ER-150; Steranti Research Ltd, St Albans), and involved extraction into diethyl ether before the assay. The assays were done 'blind' with samples in random order.

An estimate of the percentage of free $T$ was calculated $\left(\%\right.$ free $T=6 \cdot 11-2.38 \times \log _{10}$ SHBG; Nanjee \& Wheeler, 1985) and used to calculate the concentration of free T. Since free $\mathrm{T}$ is not a measured value, and was calculated using an equation derived to fit measurements of total T and SHBG made in a different laboratory, the current results for free $T$ should be interpreted with some caution. The use of a 'free androgen index' calculated as the concentration of T divided by the concentration of SHBG (Carter et al. 1983) was considered but rejected because this index is unduly sensitive to changes in SHBG. Ruutiainen et al. (1987) reported rank correlations of the free androgen index with total $\mathrm{T}$ and SHBG of 0.25 and -0.87 respectively, in comparison with correlations of measured free $T$ with total $T$ and $S H B G$ of 0.79 and -0.26 respectively. For our data, the rank correlations of calculated free $\mathrm{T}$ with total $\mathrm{T}$ and $\mathrm{SHBG}$ were 0.81 and -0.33 
Table 1. Subject characteristics of fifty-one vegans and fifty-seven omnivores

(Mean values with their standard errors)

\begin{tabular}{|c|c|c|c|c|c|}
\hline \multirow[b]{2}{*}{ Characteristic } & \multicolumn{2}{|c|}{ Vegans } & \multicolumn{2}{|c|}{ Omnivores } & \multirow{2}{*}{$\begin{array}{c}\text { Statistical } \\
\text { significance } \\
\text { of difference } \\
\text { between means } \\
P^{*}\end{array}$} \\
\hline & Mean & $\mathrm{SE}$ & Mean & $\mathrm{SE}$ & \\
\hline Age (years) & $41 \cdot 4$ & 1.6 & $40 \cdot 3$ & 1.6 & 0.629 \\
\hline Height (m) & 1.78 & 0.01 & 1.79 & 0.01 & 0.229 \\
\hline Weight (kg) & $70-3$ & 1.4 & 74.7 & $1 \cdot 3$ & 0.021 \\
\hline BMI $\left(\mathrm{kg} / \mathrm{m}^{2}\right)$ & $22 \cdot 2$ & 0.3 & $23 \cdot 2$ & 0.3 & 0.035 \\
\hline Alcohol intake $(\mathrm{g} / \mathrm{d})$ & $14 \cdot 1$ & $3 \cdot 2$ & 19.6 & $3 \cdot 0$ & 0.216 \\
\hline
\end{tabular}

BMI, body mass index.

* Two-sided test for difference between means.

respectively (i.e. very similar to those for measured free $\mathrm{T}$ reported by Ruutiainen et al. 1987), while the corresponding correlations for the free androgen index were 0.49 and $-0 \cdot 71$ respectively.

One subject was excluded from all the statistical analyses because he had a plasma $T$ concentration of only $1.4 \mathrm{nmol} / 1$ (the next lowest value was $7.3 \mathrm{nmol} / 1$ ). He was a 24 -yearold vegan with an unremarkable body mass index (BMI $\left.; 21.4 \mathrm{~kg} / \mathrm{m}^{2}\right)$, but with a high E2 $(0.51 \mathrm{nmol} / \mathrm{l})$ and a report in the recruitment questionnaire of formerly drinking 45 pints of beer weekly. The low $T$ value may have been due to an undiagnosed or unreported medical abnormality or, possibly, due to deliberate substitution of a blood sample from a woman.

\section{Nutrient intakes}

Diet records $(4 \mathrm{~d})$ had been received from eighteen of the vegans and twenty-two of the omnivores. Average daily nutrient intakes were calculated using the tables of Paul \& Southgate (1978) supplemented by other food tables (Paul et al. 1980; Wiles et al. 1980; Wharton \& Eaton, 1983; Tan et al. 1985) and by some analyses provided by food manufacturers.

\section{Statistical analyses}

T, SHBG, free T, and E2 were logarithmically transformed to achieve approximately normal distributions. Comparisons between dietary groups were made using analysis of variance. Relationships between hormones and dietary variables were examined using Pearson correlation coefficients, partial correlation coefficients and linear regression. Twosided statistical significance $(P)$ values are quoted.

\section{RESULTS}

The vegans and omnivores were of similar age, but the mean BMI of the vegans was $4 \%$ less than that of the omnivores (Table 1).

Before comparing the mean hormone concentrations in vegans and omnivores, we calculated the correlation coefficients between the hormonal variables and age, BMI, and alcohol intake (Table 2). Age was positively correlated with SHBG and inversely correlated with total $\mathrm{T}$ and, more strongly, with free $\mathrm{T}$. BMI was inversely correlated with $\mathrm{T}$ and SHBG, but was not significantly correlated with free $T$. Alcohol was weakly positively correlated with free $\mathrm{T}$ and weakly inversely correlated with SHBG, but these correlations were not statistically significant. E2 was not correlated with age, BMI or alcohol. 
Table 2. Pearson correlation coefficients between age, BMI, alcohol and log plasma hormone concentrations of fifty-one vegans and fifty-seven omnivores

(106 degrees of freedom)

\begin{tabular}{lrrrrrr}
\hline & \multicolumn{1}{c}{ Age } & BMI & Alcohol & Log T & Log SHBG & Log free T \\
\hline BMI & 0.32 & & & & & \\
Alcohol & -0.01 & 0.12 & & & & \\
Log T & -0.33 & -0.21 & 0.11 & & & \\
Log SHBG & 0.35 & -0.29 & -0.14 & 0.20 & & \\
Log free T & -0.51 & -0.05 & 0.19 & 0.85 & -0.35 & \\
Log E2 & -0.01 & -0.01 & -0.06 & 0.23 & 0.18 & 0.13 \\
\hline
\end{tabular}

Two-sided significance level: $r>0 \cdot 20, P<0.05$.

BMI, body mass index; T, testosterone; SHBG, sex hormone-binding globulin; E2, oestradiol.

Table 3. Plasma hormone concentrations of fifty-one vegans and fifty-seven omnivores (Geometric mean values with their pooled standard error ranges)

\begin{tabular}{|c|c|c|c|c|c|c|}
\hline \multirow[b]{2}{*}{$\begin{array}{l}\text { Hormone } \\
(\mathrm{nmol} / \mathrm{l})\end{array}$} & \multirow[b]{2}{*}{ Adjusted* } & \multicolumn{2}{|c|}{ Vegans } & \multicolumn{2}{|c|}{ Omnivores } & \multirow{2}{*}{$\begin{array}{l}\text { Statistical } \\
\text { significance of } \\
\text { difference } \\
\text { between } \\
\text { means: } P_{+}^{+}\end{array}$} \\
\hline & & $\begin{array}{c}\text { Geometric } \\
\text { mean }\end{array}$ & $\begin{array}{c}\text { Pooled } \\
\text { SE range } \dagger\end{array}$ & $\begin{array}{c}\text { Geometric } \\
\text { mean }\end{array}$ & $\begin{array}{c}\text { Pooled } \\
\text { SE range } \dagger\end{array}$ & \\
\hline $\mathrm{T}$ & No & $15 \cdot 2$ & $14 \cdot 6-15 \cdot 9$ & $14 \cdot 3$ & $13.8-14.9$ & 0.297 \\
\hline $\mathrm{T}$ & Yes & $15 \cdot 3$ & $14.7-15.9$ & $14 \cdot 3$ & $13 \cdot 8-14.8$ & 0.250 \\
\hline SHBG & No & $41 \cdot 3$ & $39 \cdot 2-43 \cdot 5$ & 30.7 & $29 \cdot 2-32 \cdot 3$ & $<0.001$ \\
\hline SHBG & Yes & $39 \cdot 5$ & $37 \cdot 8-41 \cdot 4$ & $32 \cdot 0$ & $30 \cdot 6-33 \cdot 3$ & 0.001 \\
\hline Free $\mathrm{T}$ & No & $0 \cdot 34$ & $0.33-0.35$ & 0.36 & $0.35-0.38$ & 0.253 \\
\hline Free $\mathrm{T}$ & Yes & $0 \cdot 35$ & $0 \cdot 33-0 \cdot 36$ & $0 \cdot 36$ & $0.35-0.37$ & 0.580 \\
\hline E2 & No & $0 \cdot 10$ & $0.09-0.11$ & $0 \cdot 09$ & $0.08-0.11$ & $0 \cdot 185$ \\
\hline E2 & Yes & $0 \cdot 10$ & $0 \cdot 09-0 \cdot 11$ & 0.09 & $0.08-0.09$ & $0 \cdot 194$ \\
\hline
\end{tabular}

T, testosterone; SHBG, sex hormone-binding globulin; E2, oestradiol.

* Adjusted for age, body mass index and alcohol intake, all as untransformed continuous variables.

$\dagger$ Antilogarithm of the mean of the logarithmically transformed values plus or minus the standard error of the mean.

+ Two-sided test for difference between means.

Table 3 shows the geometric mean values for the hormonal variables in vegans and omnivores; the values are given both 'unadjusted' and after adjustment for age, BMI and alcohol intake (adjusted by analysis of covariance, with age, BMI and alcohol as untransformed continuous variables). Adjusted mean $T$ was $7 \%$ higher in the vegans than the omnivores, but this difference did not approach statistical significance. Unadjusted SHBG was $35 \%$ higher in the vegans than the omnivores; this difference was reduced to $23 \%$ higher (but remained highly statistically significant) after adjusting for age, BMI and alcohol, largely because of the inverse relationship between SHBG and BMI (Table 2) and the lower BMI of the vegans (Table 1). Adjusted free $\mathrm{T}$ was $3 \%$ lower, and adjusted E2 was $11 \%$ higher, in the vegans than the omnivores, but these differences were not statistically significant.

Since an increase in SHBG may cause an increase in total $T$ (see Discussion), we 
Table 4. Dietary composition for eighteen vegans and twenty-two omnivores

(Mean values with their standard errors)

\begin{tabular}{|c|c|c|c|c|c|}
\hline \multirow[b]{2}{*}{ Dietary variable } & \multicolumn{2}{|c|}{ Vegans } & \multicolumn{2}{|c|}{ Omnivores } & \multirow{2}{*}{$\begin{array}{c}\text { Statistical } \\
\text { significance of } \\
\text { difference } \\
\text { between means: } \\
P^{*}\end{array}$} \\
\hline & Mean & $\mathrm{SE}$ & Mean & $\mathrm{SE}$ & \\
\hline Energy $(\mathrm{MJ} / \mathrm{d})$ & $10 \cdot 8$ & 0.7 & $10 \cdot 9$ & 0.6 & 0.885 \\
\hline Fat $(\mathrm{g} / \mathrm{d})$ & 94.7 & $9 \cdot 9$ & $111 \cdot 2$ & $9 \cdot 0$ & $0 \cdot 225$ \\
\hline SFA $(g / d)$ & 17.6 & $2 \cdot 9$ & 37.7 & $2 \cdot 6$ & $<0.001$ \\
\hline PUFA (g/d) & $30 \cdot 2$ & $3 \cdot 4$ & $21 \cdot 7$ & $3 \cdot 1$ & 0.072 \\
\hline $\mathrm{CHO}(\mathrm{g} / \mathrm{d})$ & $370 \cdot 8$ & $24 \cdot 2$ & 298.5 & $21 \cdot 8$ & 0.033 \\
\hline Protein $(\mathrm{g} / \mathrm{d})$ & $73 \cdot 0$ & $5 \cdot 8$ & 91.7 & $5 \cdot 2$ & 0.021 \\
\hline Alcohol $(\mathrm{g} / \mathrm{d})$ & $6 \cdot 3$ & 3.5 & $16 \cdot 4$ & $3 \cdot 1$ & 0.036 \\
\hline Dietary fibre $(\mathrm{g} / \mathrm{d})$ & $56 \cdot 6$ & 4.5 & $35 \cdot 1$ & $4 \cdot 0$ & 0.001 \\
\hline Fat (\% energy) & $32 \cdot 6$ & 1.9 & $38 \cdot 0$ & 1.8 & 0.046 \\
\hline SFA ( $\%$ energy) & 6.2 & 0.6 & 12.9 & 0.6 & $<0.001$ \\
\hline PUFA ( $\%$ energy) & $10 \cdot 3$ & 0.9 & $7 \cdot 2$ & 0.8 & 0.013 \\
\hline $\mathrm{CHO}(\%$ energy) & $54 \cdot 4$ & 1.7 & $43 \cdot 0$ & 1.5 & $<0.001$ \\
\hline Protein (\% energy) & 11.5 & 0.6 & $14 \cdot 4$ & 0.6 & $0 \cdot 002$ \\
\hline Alcohol ( $\%$ energy) & 1.9 & $1 \cdot 1$ & $4 \cdot 7$ & $1 \cdot 0$ & 0.056 \\
\hline
\end{tabular}

SFA, saturated fatty acids; PUFA, polyunsaturated fatty acids; $\mathrm{CHO}$, carbohydrate.

* Two-sided test for difference between means.

examined the effect on the mean T values of adjusting for SHBG (as well as for age, BMI and alcohol). This adjustment eliminated the difference in total $\mathrm{T}$ between the two groups (adjusted mean $T$ was $14.7 \mathrm{nmol} / 1$ in both vegans and omnivores).

In the subset of forty subjects for whom $4 \mathrm{~d}$ diet records were available, mean energy intake did not differ between vegans and omnivores (Table 4). Vegans consumed more polyunsaturated fat, carbohydrate and dietary fibre, and less total fat, saturated fat, protein and alcohol than the omnivores.

The relationships between the hormonal variables and these dietary variables were examined by calculating partial correlation coefficients, adjusted for age, BMI and dietary group (vegan or omnivore) (Table 5). Total $\mathrm{T}$ was significantly positively correlated with polyunsaturated fat intake. SHBG was significantly positively correlated with total fat, saturated fat and polyunsaturated fat, and was inversely correlated with alcohol intake. Free $\mathrm{T}$ and $\mathrm{E} 2$ were not significantly correlated with any of the dietary variables. These correlations were similar for nutrient intakes expressed as $\mathrm{g} / \mathrm{d}$ and nutrient intakes expressed as a percentage of energy intake. Analysis by linear regression showed that there were no significant interactions between dietary group (vegan or omnivore) and the relationships of the hormonal variables with the dietary variables.

\section{DISCUSSION}

Study design

As far as we know this is the first study of sex hormones in male vegans and is larger than the previous studies of sex hormones in male vegetarians. The study has some weaknesses because it was designed after the material had been collected for other purposes. The information on BMI, usual alcohol intake, smoking habits, long-term medication and previous diseases was taken from the recruitment questionnaire, which was collected before 
Table 5. Partial correlation coefficients, adjusted for age, body mass index and dietary group, of log plasma hormone concentrations with dietary variables for eighteen vegans and twenty-two omnivores

(35 degrees of freedom)

\begin{tabular}{|c|c|c|c|c|}
\hline Dietary variable & $\log T$ & Log SHBG & Log free $T$ & $\log \mathrm{E} 2$ \\
\hline Energy $(\mathrm{MJ} / \mathrm{d})$ & 0.26 & $0 \cdot 19$ & $0 \cdot 20$ & $-0 \cdot 11$ \\
\hline Fat $(g / d)$ & 0.22 & 0.43 & 0.03 & -0.08 \\
\hline SFA $(g / d)$ & $0 \cdot 12$ & $0 \cdot 46$ & -0.08 & $-0 \cdot 14$ \\
\hline $\operatorname{PUFA}(\mathrm{g} / \mathrm{d})$ & 0.37 & $0 \cdot 33$ & $0 \cdot 22$ & $0 \cdot 07$ \\
\hline $\mathrm{CHO}(\mathrm{g} / \mathrm{d})$ & 0.17 & -0.02 & 0.21 & -0.03 \\
\hline Protein $(g / d)$ & $0 \cdot 16$ & $0 \cdot 17$ & $0 \cdot 10$ & -0.27 \\
\hline Alcohol $(\mathrm{g} / \mathrm{d})$ & 0.14 & -0.39 & $0 \cdot 30$ & -0.07 \\
\hline Dietary fibre $(\mathrm{g} / \mathrm{d})$ & 0.09 & -0.04 & $0 \cdot 12$ & $-0 \cdot 08$ \\
\hline Fat ( $\%$ energy) & 0.07 & 0.51 & $-0 \cdot 16$ & $-0 \cdot 05$ \\
\hline SFA ( $\%$ energy) & -0.06 & 0.47 & -0.27 & $-0 \cdot 12$ \\
\hline PUFA (\% energy) & 0.36 & $0 \cdot 36$ & $0 \cdot 18$ & $0 \cdot 16$ \\
\hline $\mathrm{CHO}(\%$ energy) & -0.06 & -0.29 & 0.09 & $0 \cdot 16$ \\
\hline Protein (\% energy) & -0.13 & 0.01 & -0.13 & $-0 \cdot 24$ \\
\hline Alcohol (\% energy) & 0.03 & -0.47 & $0 \cdot 21$ & -0.02 \\
\hline
\end{tabular}

Two-sided significance level: $r>0 \cdot 33, P<0 \cdot 05$.

T, testosterone; SHBG, sex hormone-binding globulin; E2, oestradiol; SFA, saturated fatty acids; PUFA, polyunsaturated fatty acids; $\mathrm{CHO}$, carbohydrate.

the blood sample. The $4 \mathrm{~d}$ diet record was collected after the blood sample. There must therefore be some misclassification for the variables derived from the questionnaires. Total $T$ varies during the day with higher values in the morning, but we have no information on when the blood samples were taken. These sources of error would be expected to be randomly distributed between vegans and omnivores, and between subjects with different dietary compositions, and should therefore slightly reduce the strength of any relationships observed but should not bias the results.

Our confidence in the validity of these results is increased by those findings which replicate the well-established findings of other groups. For example, we found that total $\mathrm{T}$ and free $\mathrm{T}$ decrease with age (Dai et al. 1981), that SHBG increases with age (BarrettConnor \& Khaw, 1987), and that total T and SHBG decrease with increasing BMI (Kley et al. 1979). The differences in dietary composition between vegans and omnivores were also quite consistent with the results of previous studies (Abdulla et al. 1981; Lockie et al. 1985; Sanders \& Key, 1987).

\section{Comparison of vegans and omnivores}

Total $\mathrm{T}$ was $7 \%$ higher in the vegans than the omnivores, and this difference was reduced to zero by adjusting for SHBG. Although there have been some previous studies of $\mathrm{T}$ in male vegetarians, this is the first report of $T$ in male vegans. Howie \& Shultz (1985) reported that mean $\mathrm{T}$ was $18 \%$ lower in male Seventh Day Adventist vegetarians than in omnivores, but this result was based on only twelve vegetarians. In a larger study, Deslypere \& Vermeulen (1984) reported no difference in $T$ between thirty-five vegetarian men and fortynine omnivores. Another recent small study (fifteen vegetarians, fourteen omnivores) reported that mean $\mathrm{T}$ was $31 \%$ higher in the vegetarians, but this difference may have been at least partly due to the $11 \%$ lower BMI of the vegetarians (Belanger et al. 1989).

Three small studies have reported that changing the usual diet of omnivorous men to a vegetarian or 'semi-vegetarian' (low-fat) diet causes a fall in $\mathrm{T}$ in men (Hill \& Wynder, 
1979; Hill et al. 1980; Hamalainen et al. 1984). However, in another small study a very lowfat, almost vegetarian diet did not cause a decrease in $\mathrm{T}$ (but did cause substantial decreases in E2 and cholesterol; Rosenthal et al. 1985), and a fall in T was observed when the black South African men in the study of Hill et al. (1980) changed their usual vegetarian diet to a Western diet. It is possible, therefore, that a sudden substantial change in diet causes a fall in $\mathrm{T}$ regardless of the 'direction' of the change in diet composition. We draw the tentative conclusion that the differences in dietary composition between usual Western vegan and omnivore diets do not have any substantial effect on total $T$.

Most of the previous studies of the effects of a vegetarian diet on hormones have not measured SHBG. Hamalainen et al. (1984) observed a non-significant $9 \%$ decrease in SHBG in men changing to a semi-vegetarian diet. Belanger et al. (1989) found that mean SHBG was $47 \%$ higher in the vegetarians, but it is difficult to interpret this result because the mean BMI of the vegetarians was $11 \%$ lower than that of the omnivores and BMI is strongly inversely related to SHBG (Moore \& Bulbrook, 1988). The $23 \%$ higher SHBG in vegans than in omnivores which we observed after adjusting for BMI was highly statistically significant, but needs confirmation in another study.

Among the studies of the effects of a vegetarian or semi-vegetarian diet on $T$ (discussed previously), only two reported results for free T. Of these two, Deslypere \& Vermeulen (1984) found no difference in free $T$ between vegetarians and omnivores, but Hamalainen et al. (1984) found a $13 \%$ decrease in free $\mathrm{T}$ following a change to a semi-vegetarian diet. Belanger et al. (1989) reported that the mean free androgen index was lower in vegetarians than omnivores, but as noted previously ( $\mathrm{pp} .112-113$ ) this index is unduly sensitive to SHBG, which was substantially higher in the vegetarians. The current study provided no evidence that calculated free $T$ is lower in vegans than in omnivores.

A plausible explanation of the results for total $T, S H B G$, and free $T$ in vegans is that a vegan diet causes an increase in SHBG, but does not affect the homeostatic control of the concentration of free $\mathrm{T}$. The $7 \%$ difference in total $\mathrm{T}$ between the vegans and omnivores was not statistically significant, but probably represents a real difference in total $T$ which is needed to maintain the concentration of free $T$ in the face of the decrease in the percentage of free $T$ in the vegans caused by the increase in SHBG (Dunn et al. 1981). This conclusion is supported by the observation that the $7 \%$ difference in total $T$ was eliminated by adjusting for SHBG.

Neither the current study nor those of Deslypere \& Vermeulen (1984) and Belanger et al. (1989) found any difference in E2 between vegans or vegetarians and omnivores. Howie \& Shultz (1985) reported a $40 \%$ lower mean E2 in vegetarians than in omnivores, but, as noted previously, there were only twelve vegetarians in their study.

\section{Correlations of dietary components with hormones}

This part of the analysis was done partly to generate new hypotheses and partly to test the specific hypotheses that dietary fibre would be directly correlated with SHBG and inversely correlated with E2. Neither of these hypotheses was supported by the findings. One possible problem with the interpretation of our findings is that, although the mean dietary fibre intake of the vegans was $61 \%$ higher than that of the omnivores, the omnivores themselves had a high intake of fibre $(35.1 \mathrm{~g} / \mathrm{d})$. This is because the omnivores in the present study were, on average, of high social class and following a 'prudent diet'. It is conceivable that fibre intake is related to SHBG and E2 at the lower end of the range of possible intakes, but that above this end of the range there is a 'plateau' effect.

Examination of the relationship of SHBG with dietary fibre intake was of particular interest because of the previous reports of a positive correlation between SHBG and fibre in both men (Bishop et al. 1988) and women (Adlercreutz et al. 1987), and because the first 
part of the current analysis had shown higher SHBG in the vegans. At that stage it appeared possible that the higher SHBG of the vegans might be explained by their higher fibre intake, and we expected to find some correlation between the two variables because of the substantially higher values for both SHBG and fibre in the vegans. The low correlation $(r-0.04)$ between the two variables was, therefore, surprising. It is possible that a high dietary intake of phyto-oestrogens is the cause of the high SHBG of the vegans in the current study, but we have no information on this.

There was no significant correlation between dietary fibre and E2 in the current study $(r-0.08)$, providing no support for the hypothesis that a high intake of dietary fibre may reduce the enterohepatic circulation of $\mathrm{E} 2$ and, thus, reduce the plasma concentration of E2 (Goldin et al. 1982). Goldin et al. (1982) made this suggestion on the basis of a study of premenopausal women, but it seems reasonable to suppose that any effect of fibre on plasma E2 would, if anything, be more likely to be observed in men, because (as far as is known) there is no direct feedback mechanism to maintain plasma E2 at a set level in men.

Some previous studies have reported a weak inverse correlation between SHBG (or the T binding capacity of plasma) and alcohol intake (Sparrow et al. 1980; Stefanick et al. 1987), while others have found no relationship between these variables (Lindholm et al. 1982; Heller et al. 1983). In the current study, the inverse correlation between SHBG and alcohol was stronger in the subset of forty men for whom $4 \mathrm{~d}$ diet records were available $(r-0.39)$ than in all 108 men for whom a record of usual alcohol intake was available $(r-0 \cdot 14)$. Neither record of alcohol intake was for the exact period of blood collection. Our results support the suggestion, from some previous studies, of a weak inverse relationship between alcohol and SHBG. Such a relationship could well be causal because alcohol has many effects on the liver, the main site of SHBG synthesis (Anderson, 1974).

The positive correlations between total $T$ and polyunsaturated fat and between SHBG and total, saturated, and polyunsaturated fat were not prior hypotheses and must therefore be interpreted cautiously.

\section{REFERENCES}

Abdulla, M., Andersson, I., Asp, N.-G., Berthelsen, K., Birkhed, D., Dencker, I., Johansson, C.-G., Jagerstad, M., Kolar, K., Nair, B. M., Nilsson-Ehle, P., Norden, A., Rassner, S., Akesson, B. \& Ockerman, P.-A. (1981). Nutrient intake and health status of vegans. Chemical analyses of diets using the duplicate portion sampling technique. American Journal of Clinical Nutrition 34, 2464-2477.

Adlercreutz, H., Hockerstedt, K., Bannwart, C., Bloigu, S., Hamalainen, E., Fotsis, T. \& Ollus, A. (1987). Effect of dietary components, including lignans and phytoestrogens, on enterohepatic circulation and liver metabolism of estrogens and on sex hormone binding globulin (SHBG). Journal of Steroid Biochemistry 27, 1135-1144.

Anderson, D. C. (1974), Sex-hormone-binding globulin. Clinical Endocrinology 3, 69-96.

Barrett-Connor, E. \& Khaw, K.-T. (1987). Cigarette smoking and increased endogenous estrogen levels in men. American Journal of Epidemiology 126, 187-192.

Belanger, A., Locong, A., Noel, C., Cusan, L., Dupont, A., Prevost, J., Caron, S. \& Sevigny, J. (1989). Influence of diet on plasma steroid and sex plasma binding globulin levels in adult men. Journal of Steroid Biochemistry 32, 829-833.

Bishop, D. T., Meikle, A. W., Slattery, M. L., Stringham, J. D., Ford, M. H. \& West, D. W. (1988). The effect of nutritional factors on sex hormone levels in male twins. Genetic Epidemiciogy 5, 43-59,

Carter, G. D., Holland, S. M., Alaghband-Zadeh, J., Rayman, G., Dorrington-Ward, P. \& Wise P. H. (1983). Investigation of hirsutism: testosterone is not enough. Annals of Clinical Biochemistry 20, 262-263.

Dai, W. S., Kuller, L. H., LaPorte, R. E., Gutai, J. P., Falvo-Gerard, L. \& Caggiula, A. (1981). The epidemiology of plasma testosterone levels in middle-aged men. American Journal of Epidemiology 114, 804-816.

Deslypere, J. P. \& Vermeulen, A. (1984). Leydig cell function in normal men: effect of age, life-style, residence, diet, and activity. Journal of Clinical Endocrinology and Metabolism 59, 955-962.

Dunn, J. F., Nisula, B. C. \& Rodbard, D. (1981). Transport of steroid hormones: binding of 21 endogenous steroids to both testosterone-binding globulin and corticosteroid-binding globulin in human plasma. Journal of Clinical Endocrinology and Metabolism 53, 58-68.

Goldin, B. R., Adlercreutz, H., Gorbach, S. L., Warram, J. H., Dwyer, J. T., Swenson, L. \& Woods, M. N. (1982). Estrogen excretion patterns and plasma levels in vegetarian and omnivorous women. New England Journal of Medicine 307, 1542-1547. 
Hamalainen, E., Adlercreutz, H., Puska, P. \& Pietinen, P. (1984). Diet and serum sex hormones in healthy men. Journal of Steroid Biochemistry 20, 459-464.

Heller, R. F., Wheeler, M. J., Micallef, J., Miller, N. E. \& Lewis, B. (1983). Relationship of high density lipoprotein cholesterol with total and free testosterone and sex hormone binding globulin. Acta Endocrinologica 104, 253-256.

Henderson, B. E., Ross, R. K., Pike, M. C. \& Casagrande, J. T. (1982). Endogenous hormones as a major factor in human cancer. Cancer Research 42, 3232-3239.

Hill, P. B. \& Wynder, E. L. (1979). Effect of a vegetarian diet and dexamethasone on plasma prolactin, testosterone and dehydroepiandrosterone in men and women. Cancer Letters 7, 273-282.

Hill, P., Wynder, E., Garbaczewski, L., Garnes, H., Walker, A. R. P. \& Helman, P. (1980). Plasma hormones and lipids in men at different risk for coronary heart disease. American Journal of Clinical Nutrition 33, 1010-1018

Howie, B. J. \& Shultz, T. D. (1985). Dietary and hormonal interrelationships among vegetarian Seventh-Day Adventists and nonvegetarian men. American Journal of Clinical Nutrition 42, 127-134.

Kley, H. K., Solbach, H. G., McKinnan, J. C. \& Kruskemper, H. L. (1979). Testosterone decrease and oestrogen increase in male patients with obesity. Acta Endocrinologica 91, 553-563.

Lindholm, J., Winkel, P., Brodthagen, U. \& Gyntelberg, F. (1982). Coronary risk factors and plasma sex hormones. American Journal of Medicine 73, 648-651.

Lockie, A. H., Carlson, E., Kipps, M. \& Thomson, J. (1985). Comparison of four types of diet using clinical, laboratory and psychological studies. Journal of the Royal College of General Practitioners 35, 333-336.

Mendel, C. M., Murai, J. T., Siiteri, P. K., Monroe, S. E. \& Inoue, M. (1989). Conservation of free but not total or non-sex hormone-binding-globulin-bound testosterone in serum from Nagase analbuminemic rats. Endocrinology 124, 3128-3130.

Moore, J. W. \& Bulbrook, R. D. (1988). The epidemiology and function of sex hormone-binding globulin. In Oxford Reviews of Reproductive Biology, vol. 10, pp. 180-236 [J. Clarke, editor]. Oxford: Oxford University Press.

Nanjee, M. N. \& Wheeler, M. J. (1985). Plasma free testosterone - is an index sufficient? Annals of Clinical Biochemistry 22, 387-390.

Paul, A. A. \& Southgate, D. A. T. (1978). McCance and Widdowson's The Composition of Foods, 4th ed. London: H.M. Stationery Office.

Paul, A. A., Southgate, D. A. T. \& Russell, J. (1980). First Supplement to McCance and Widdowson's The Composition of Foods. London: H.M. Stationery Office.

Rose, D. P. (1986). The biochemical epidemiology of prostatic carcinoma. Progress in Clinical and Biological Research 222, 43-68.

Rosenthal, M. B., Barnard, R. J., Rose, D. P., Inkeles, S., Hall, J. \& Pritikin, N. (1985). Effects of a high-complexcarbohydrate, low-fat, low-cholesterol diet on levels of serum lipids and estradiol. American Journal of Medicine 78, 23-27.

Ruutiainen, K., Sannikka, E., Santti, R., Erkkola, R. \& Adlercreutz, H. (1987). Salivary testosterone in hirsutism : correlations with serum testosterone and the degree of hair growth. Journal of Clinical Endocrinology and Metabolism 64, 1015-1020.

Sanders, T. A. B. \& Key, T. J. A. (1987). Blood pressure, plasma renin activity and aldosterone concentrations in vegans and omnivore controls. Human Nutrition: Applied Nutrition 41A, 204-211.

Sparrow, D., Bosse, R. \& Rowe, J. W. (1980). The influence of age, alcohol consumption, and body build on gonadal function in men. Journal of Clinical Endocrinology and Metabolism 51, 508-512.

Stefanick, M. L., Williams, P. T., Krauss, R. M., Terry, R. B., Vranizan, K. M. \& Wood, P. D. (1987). Relationships of plasma estradiol, testosterone, and sex hormone-binding globulin with lipoproteins, apolipoproteins, and high density lipoprotein subfractions in men. Journal of Clinical Endocrinology and Metabolism 64, 723-729.

Tan, S. P., Wenlock, R. W. \& Buss, D. H. (1985). Immigrant foods. Second Supplement to McCance and Widdowson's The Composition of Foods. London: H.M. Stationery Office.

Thorogood, M., Carter, R., Benfield, L., McPherson, K. \& Mann, J. I. (1987). Plasma lipids and lipoprotein cholesterol concentrations in people with different diets in Britain. British Medical Journal 295, 351-353.

Wharton, P. A. \& Eaton, P. M. (1983). Sorrento Asian food tables: food tables, recipes and customs of mothers attending Sorrento Maternity Hospital, Birmingham, England. Human Nutrition: Applied Nutrition 37A, $378-402$.

Wiles, S. J., Nettleton, P. A., Black, A. E. \& Paul, A. A. (1980). The nutrient composition of some cooked dishes eaten in Britain: a supplementary food composition table. Journal of Human Nutrition 34, 189-223. 